\title{
Expression and Localization of the Cystic Fibrosis Transmembrane Conductance Regulator mRNA and Its Protein in Rat Brain
}

\author{
Andrew E. Mulberg, ${ }^{*}$ Lee P. Resta, ${ }^{\star}$ Ellen B. Wiedner, ${ }^{\star}$ Steven M. Altschuler, ${ }^{*}$ Douglas M. Jefferson, ${ }^{*}$ \\ and Delma L. Broussard* \\ *Division of Gastroenterology and Nutrition, Children's Hospital of Philadelphia, Department of Pediatrics, University of Pennsylvania \\ School of Medicine, Philadelphia, Pennsylvania 19104; and the ${ }^{\ddagger}$ Departments of Pediatrics, Medicine and Physiology, Tufts University \\ School of Medicine, Boston, Massachusetts 02115
}

\begin{abstract}
In previous studies we have characterized the expression of the cystic fibrosis transmembrane conductance regulator (CFTR) protein in clathrin-coated vesicles derived from bovine brain and in neurons of rat brain. In this study we have further characterized the expression of the CFTR protein mRNA and protein in rat brain with reverse transcriptase polymerase chain reaction amplification (RTPCR), in situ hybridization, and immunocytochemistry. The expression of CFTR mRNA and protein in discrete areas of brain, including the hypothalamus, thalamus, and amygdaloid nuclei, which are involved in regulation of appetite and resting energy expenditure, is identical. The presence of CFTR in neurons localized to these regions of brain controlling homeostasis and energy expenditure may elucidate the pathogenesis of other nonpulmonary and gastrointestinal manifestations which commonly are observed in children with cystic fibrosis. Dysregulation of normal neuropeptide vesicle trafficking by mutant CFTR in brain may serve as a pathogenic mechanism for disruption of homeostasis. (J. Clin. Invest. 1995. 96:646-652.) Key words: cystic fibrosis • neuropeptide secretion • vesicle trafficking • energy expenditure
\end{abstract}

\section{Introduction}

Cystic fibrosis $(\mathrm{CF})^{1}$ is characterized by defective electrolyte transport in epithelial cells of several organ systems including the lung, liver, intestine, and pancreas (1-4). Other clinical

Address correspondence to Andrew E. Mulberg, Division of Pediatric Gastroenterology and Nutrition, The Children's Hospital of Philadelphia, 34th Street and Civic Center Blvd., Philadelphia, PA 19104. Phone: 215-590-3067; FAX: 215-590-3680.

Received for publication 22 February 1994 and accepted in revised form 6 April 1995.

1. Abbreviations used in this paper: CF, cystic fibrosis; CFTR, CF transmembrane conductance regulator; NPY, neuropeptide Y; RT-PCR, reverse transcriptase PCR.

J. Clin. Invest.

(C) The American Society for Clinical Investigation, Inc.

0021-9738/95/07/0646/07 \$2.00

Volume 96, July 1995, 646-652 manifestations that are observed include subnormal height and weight related to malabsorption, pancreatic insufficiency, anorexia, and increased resting and total energy needs (5-8). The gene responsible for CF encodes a 1480 amino acid protein which has been sequenced, termed the cystic fibrosis transmembrane conductance regulator (CFTR). The primary structure of CFTR consists of 12 transmembrane-spanning domains, 2 nucleotide-binding domains (NBF1 and NBF2), and a regulatory domain (R domain) (9). In addition to CFTR functioning as a cAMP-dependent chloride channel in epithelial tissues, CFTR is a cAMP-dependent water and bicarbonate channel, a regulator of membrane recycling, and a modulator of the outwardly rectified chloride channel (10-15).

Regulation of vacuolar $\mathrm{pH}$ in intracellular organelles plays a critical role in receptor-mediated endocytosis, intracellular membrane trafficking, and secretion. If the cystic fibrosis phenotype is expressed intracellularly, vacuolar acidification in epithelia expressing the CF defect would be abnormal (16). CFTR expression has been demonstrated at the ultrastructural level in sweat duct endosomes and may regulate vacuolar acidification (17-20). Whether receptor-mediated endocytosis, membrane trafficking, and targeting of proteins in any affected organ are defective in CF remains to be confirmed. Our previous work has demonstrated that a common mechanism is used in the protein kinase $\mathrm{A}$-dependent phosphorylation regulation of chloride channels in plasma membrane, and in intracellular chloride channels of clathrin-coated vesicles derived from bovine brain $(21,22)$. The identification of CFTR within clathrincoated vesicles derived from bovine brain and expression of CFTR in rat brain lends support for its role in intracellular functions. Neuron-specific CFTR function could regulate neurotransmitter-dependent control of energy expenditure.

To understand the potential regulation of membrane trafficking by CFTR, we extend our previous observation by demonstrating that multiple areas of the rat brain, express CFTR protein and mRNA (21). Whether CFTR regulates neuropeptide secretion, neurotransmission, and abnormal homeostatic functions in humans remains unknown. We propose that other common nonpulmonary manifestations of $\mathrm{CF}$, although not representing obvious cortical dysfunction, may reflect altered neuronal functions through disruption of normal neuropeptide vesicle trafficking by mutant CFTR.

\section{Methods}

Cell and tissue preparation. NIH 3T3 and 3T3-CFTR cells were a gift of Michael Welsh of the University of Iowa. The cells were grown in 
Dulbecco's modified medium (Irvine Scientific, Santa Ana, CA) with $10 \%$ FBS (Intergen Co. Purchase, NY) and 1\% penicillin/streptomyocin (GIBCO BRL, Gaithersburg, $\mathrm{MD}$ ) in a $5 \% \mathrm{CO}_{2}$ humidified atmosphere at $37^{\circ} \mathrm{C}$. The 3T3-CFTR cells were split or fed every $2-3 \mathrm{~d}$ and harvested with trypsin-EDTA (GIBCO BRL) for RNA isolation (see below).

Animal model and rat brain preparation. Sprague-Dawley rats weighing from 250 to 500 grams were fed ad lib. within the Live Animal Facility at the Children's Hospital of Philadelphia with rat chow (Ralston Purina Co., St. Louis, MO) and water until death. Rats were anesthetized with intramuscular ketamine $(85 \mathrm{mg} / \mathrm{kg})$ and xylazine (12 $\mathrm{mg} / \mathrm{kg}$ ) and perfused transcardially with heparinized PBS and $4 \%$ paraformaldehyde. After perfusion cervical dislocation was performed and brains were harvested for experiments detailed below. All studies were approved by the Institutional Animal Care and Usage Committee at the Children's Hospital of Philadelphia.

Peptide synthesis and antibody generation. Affinity-purified polyclonal peptide antibodies, pAb3145 and pAb3147, were prepared through immunization of rabbits with the peptide antigen, KEETEEEVQDTRL, derived from the $\mathrm{COOH}$-terminal amino acids (sequence no. amino acids $1468-1480$ of the human CFTR protein) $(23,24) .600$ $\mu \mathrm{l}$ rabbit sera was applied to a 2 -ml peptide-conjugated epoxy-Sepharose 6B column (Sigma Chemical Co., St. Louis, MO) prepared through standard protocol and incubated at $4^{\circ} \mathrm{C}$ overnight. Elution conditions of the column were those described previously $(23,24)$.

Epitope mapping of specific anti-CFTR antibodies, pAb3145 and pAb3147. The exact site of recognition by antibodies, pAb3145 and pAb3147, was determined using the SPOTS methodology (Cambridge Research Biochemicals, Cambridge, MA). This protocol involves the reaction of an amino acid to an activated membrane followed by deprotection and further sequential amino acid addition to generate many short overlapping peptides. This reaction technique generated the peptide sequence, KPQIAALKEETEEEVQDTRL, containing the CFTR terminal sequence. The test antibodies, pAb3145, pAb3147, monoclonal antibody 24-1 (Genzyme Corp., Cambridge, MA) and $\alpha$-1468 (23, 24) were incubated with the peptide membrane and reaction was detected by chemiluminescence (Amersham Corp., Arlington Heights, IL) with goat anti-rabbit or goat anti-mouse horseradish peroxidase conjugate (Cappel Laboratories, Cochranville, PA).

Immunocytochemical localization of CFTR in rat brain. Rats were anaesthetized as described above. After perfusion with heparinized PBS, a periodate-lysine-paraformaldehyde fixative (PLP: 2.14 gram sodium $m$-periodate, 13.7 gram DL-lysine, and $\mathbf{4 0}$ gram paraformaldehyde [all from Sigma Chemical Co.]) in 1 liter PBS was administered. The brain and cervical spinal cord were removed, postfixed in PLP for $3 \mathrm{~h}$ at $4^{\circ} \mathrm{C}$ and then cryoprotected in $20 \%$ sucrose solution overnight at $4^{\circ} \mathrm{C}$. Frozen $30-\mu \mathrm{m}$ sections were cut sagitally or transversely and processed immunocytochemically using the avidin-biotin complex (ABC; Vector Laboratories, Inc., Burlingame, CA) immunoperoxidase method (25). Tissue sections were then rinsed several times in PBS, immersed in normal goat serum for $1 \mathrm{~h}$ and rinsed again with PBS. The tissue sections were incubated for $72 \mathrm{~h}$ in pAb3145 or pAb3147 in a 1:500 dilution of solution containing 0.5 gram BSA and $200 \mu \mathrm{l}$ Triton X-100 in $100 \mathrm{ml}$ PBS. Biotinylation with anti-rabbit IgG (Vector Laboratories, Inc.) diluted 1:100 for $90 \mathrm{~min}$ was performed. 3,3'-diaminobenzidine tetrahydrochloride (DAB; Sigma Chemical Co.) was used as substrate (26). The tissue sections were rinsed in distilled water, dehydrated in graded alcohols, cleared in xylene, and coverslipped with DPX (Fluka Chemical Corp., Ronkonkoma, NY). All photomicrographs were obtained from a DMR Research Microscope (E. Leitz, Inc., Rockleigh, NJ).

$R N A$ extraction and reverse transcriptase-PCR (RT-PCR). Total RNA was isolated from 3T3-CFTR cells and rat brain by solubilization in $4 \mathrm{M}$ guanidinium thiocyanate/0.1 M 2-mercaptoethanol, and subsequently processed using phenol and chloroform:2-propanol to remove proteins and DNA $(27,28)$. RNA was precipitated with 2-propanol and purified with a $75 \%$ ethanol wash. The isolated RNA was quantitated by ultraviolet spectrophotometry and analyzed by formaldehyde gel electrophoresis.

Oligonucleotide primers were chosen from human CFTR exons 14 and 15 to amplify a 257-bp fragment of rat CFTR, with sequences of the primers: 258-bp sense, 5 '-GACTACATGGAACACATACCTTCG$3^{\prime}$ (bases 2661-2684) and antisense, 5'-ATAGCAAGCAAAGTGTCGGCTACTC-3' (bases 2918-2894) (29). The cDNA synthesis reaction consisted of $2 \mu \mathrm{g}$ total RNA, $5 \mathrm{mM} \mathrm{MgCl}, 1 \mathrm{mM}$ dATP, dGTP, dTTP, and dCTP, $0.5 \mu \mathrm{g}$ oligo dT primer, $10 \mathrm{U}$ RNasin ribonuclease inhibitor (Promega Corp., Madison, WI), 100 U Superscript II reverse transcriptase (GIBCO BRL), 1× PCR buffer II (Perkin-Elmer Corp., Norwalk, CT), with nuclease-free water brought to a total 20- $\mu$ l reaction volume in thin-walled microcentrifuge tubes. Controls included water as a negative control, kanamycin RNA reverse transcription positive control (Promega Corp.), and a plasmid, pMTCFTR, containing the fulllength human CFTR cDNA (generously provided by Genzyme Corp.). Tubulin RNA was reverse transcribed from the 3T3-CFTR and rat brain total RNA samples in separate reactions to check the integrity of the RNA samples using the $\alpha$-tubulin sense primer, 5'-AAGAAGTCCAAGCTGGAGTTC (bases 190-210, rodent; 160-180, human), and the antisense primer, GTTGGTCTGGAATTCTGTCAG (bases 477457 , rodent; $447-427$, human $)(30,31)$. The reaction mixture was incubated for $1 \mathrm{~h}$ at $42^{\circ} \mathrm{C}$ in the OmniGene Thermal Cycling System (National Labnet Co., Woodbridge, $\mathrm{NJ}$ ), followed by a heat-inactivation step of $70^{\circ} \mathrm{C}$ for $15 \mathrm{~min}$. The cDNA was amplified directly from the cDNA synthesis reaction mix in a PCR reaction consisting of $2 \mathrm{mM}$ $\mathrm{MgCl}_{2}, 100 \mathrm{nM}$ sense primer, $100 \mathrm{nM}$ antisense primer, $2.5 \mathrm{U}$ AmpliTaq polymerase (Perkin-Elmer Corp.), $1 \times$ PCR buffer II (Perkin-Elmer Corp.), and nuclease-free water in $100 \mu \mathrm{l}$ reaction volume. The PCR reaction proceeded for 45 cycles: $94^{\circ} \mathrm{C}$ for $1 \mathrm{~min} ; 60^{\circ} \mathrm{C}$ for $45 \mathrm{~s} ; 7^{\circ} \mathrm{C}$ for $1 \mathrm{~min}$ (plus an incremental $1 \mathrm{~s} /$ cycle). The first PCR cycle was preceded by a $94^{\circ} \mathrm{C}$ incubation for $2 \mathrm{~min}$; the final cycle was followed by a $72^{\circ} \mathrm{C}$ extension for $5 \mathrm{~min}$. Products were electrophoresed on $1.5 \%$ agarose gels stained with ethidium bromide.

Southern blotting of RT-PCR products from 3T3-CFTR and rat brain $R N A$. The agarose gel was denatured for $30 \mathrm{~min}$ in $0.4 \mathrm{M} \mathrm{NaOH} / 0.6$

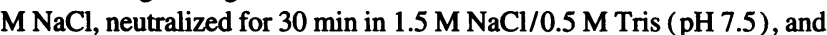
blotted to GeneScreen nitrocellulose (NEN Research Products, Beverly, MA). Cross-linking to nitrocellulose was ensured by exposure to 130 $\mathrm{mJ}$ in a ultraviolet Stratalinker 2400 (Stratagene Inc., LaJolla, CA). RT-PCR products were identified using Southern blot analysis, with an enhanced chemiluminescent (ECL) system (Amersham Corp.). An oligonucleotide ( 5 '-CAAATAAAGAAGCAGCCACCTC-3') probe between the two primers in the rat CFTR sequence, was chosen to increase specificity of base pair homology since there is not $100 \%$ sequence homology between the human and rat CFTR gene $(9,32)$. The probe was labeled at the $3^{\prime}$ end with fluorescein using terminal transferase following the manufacturer's protocol. The blots were prehybridized for $30 \mathrm{~min}$ at $42^{\circ} \mathrm{C}$ in the following solution: $5 \times \operatorname{SSC}(1.5 \mathrm{M}$ $\mathrm{NaCl}, 0.15 \mathrm{M}$ sodium citrate), $0.02 \% \mathrm{SDS}, 0.1 \%$ hybridization powder, and $0.5 \%$ blocking agent provided (Amersham Corp.). Blots were hybridized with labeled probe $(7.5 \mathrm{ng} / \mathrm{ml})$ for $2 \mathrm{~h}$ at $42^{\circ} \mathrm{C}$ in the same solution as that used for prehybridization reaction. After two washes in $5 \times \mathrm{SSC} / 0.1 \%$ SDS for $10 \mathrm{~min}$ at room temperature and twice with $1 \times \mathrm{SSC} / 0.1 \% \mathrm{SDS}$ for $15 \mathrm{~min}$ at $45^{\circ} \mathrm{C}$, blots were incubated with an antifluorescein antibody conjugated to horseradish peroxidase for 30 min and developed according to manufacturer's protocol (Amersham Corp.). Blots were then exposed to autoradiographic film (Fuji Photofilm Co., Tokyo, Japan) at room temperature for $2 \mathrm{~min}$ and developed.

Nested PCR and cloning into expression vector, pGEM-T. RT-PCR amplification products from pMT-CFTR human plasmid control, 3T3CFTR RNA and rat brain RNA were purified with the QIAquick PCR Purification Kit (QIAGEN Inc., Chatsworth, CA). Purified products were amplified by PCR using the same sense primer as previously used and an internal antisense primer, 5'-CAAATAAAGAAGCAGCCACCTC-3' derived from the rat CFTR sequence, resulting in a 110-bp product. In $50 \mu \mathrm{l}$ reaction volume, $2-5 \mathrm{ng}$ of the first RT-PCR product, 


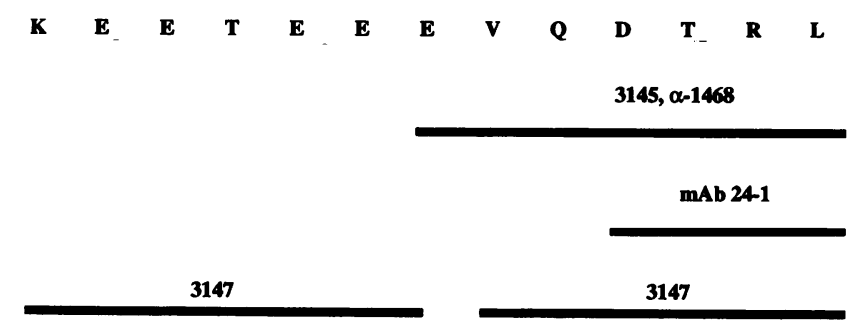

Figure 1. pAb3145 and 3147 refer to polyclonal antibodies specific for CFTR as described in the text. mAb 24-1 refers to the monoclonal antibody (Genzyme Corp.) specific to the COOH-terminus of the CFTR protein. $\alpha-1468$ refers to the polyclonal antibody produced against the COOH-terminal tridecapeptide of CFTR.

$2 \mathrm{mM} \mathrm{MgCl}{ }_{2}, 0.2 \mathrm{mM}$ dATP, dTTP, dGTP, and dCTP, $1 \times$ PCR buffer (Promega Corp.) $0.2 \mu \mathrm{M}$ each primer, $2.5 \mathrm{U}$ Taq polymerase (Promega Corp.) and nuclease-free water were added. This reaction proceeded for 15 cycles: $94^{\circ} \mathrm{C}$ for $1 \mathrm{~min} ; 60^{\circ} \mathrm{C}$ for $45 \mathrm{~s} ; 72^{\circ} \mathrm{C}$ for $1 \mathrm{~min}$ (plus an incremental 1 s/cycle). Nested PCR products were electrophoresed on agarose gels and stained with ethidium bromide.

Cloning of the nested PCR product from rat brain into the pGEM$T$ expression vector was done according to manufacturer's protocol with an insert-to-vector molar ratio of 10:1 (Promega Corp.). The resulting plasmid was referred to as the RBCFTR14-1 and was used as the template for the in vitro transcription reaction of sense and antisense riboprobes as described below. The insert CFTR sequence of RBCFTR141 was analyzed by automated fluorescence sequencing and homology was determined by comparing the gene sequences directly from published work $(9,32)$.

In situ hybridization of CFTR mRNA. The CFTR/pGEM-T clone (RBCFTR14-1) was linearized by separate restriction digestion using SpeI and SacII. Digoxygenin-labeled sense and antisense RNA probes were made by in vitro transcription by T7 RNA polymerase (Promega Corp.) and SP6 RNA polymerase (Promega Corp.), using the Genius 4 RNA Labeling Kit (Boehringer-Mannheim Biochemicals, Indianapolis, IN). The yield of digoxygenin-labeled RNA was quantitated using the Genius 3 Nucleic Acid Detection Kit (Boehringer-Mannheim Biochemicals).

$30-\mu \mathrm{m}$ sections were cut transversely using a freezing microtome (E. Leitz, Inc.) as previously described above. The protocol was adapted from that previously published, using diethylpyrocarbonate (DEPC)treated solutions (33). Sections were washed twice for $5 \mathrm{~min}$ in $1 \times$ PBS and in $1 \times$ PBS $/ 0.1 \%$ Tween-20 (PTW). Sections were prehybridized at $55^{\circ} \mathrm{C}$ for $1 \mathrm{~h}$ in $50 \%$ formamide, $5 \times \mathrm{SSC}, 100 \mu \mathrm{g} / \mathrm{ml}$ Torula yeast RNA (Sigma Chemical Co.), $100 \mu \mathrm{g} / \mathrm{ml}$ wheat germ tRNA (Sigma Chemical Co.), $50 \mu \mathrm{g} / \mathrm{ml}$ heparin, and $0.1 \%$ Tween- 20 . Sections were then incubated at $55^{\circ} \mathrm{C}$ for $16 \mathrm{~h}$ in hybridization solution with $2.5 \mu \mathrm{g} / \mathrm{ml}$ sense or antisense cRNA probes. After three 15-min washes in PTW and subsequently, in solution containing $1 \times \mathrm{PBS}, 0.1 \% \mathrm{BSA}, 0.2 \%$ Triton $\mathrm{X}-100$ solution (PBT), sections were incubated at room temperature for $1 \mathrm{~h}$ in PBT containing $0.67 \mathrm{U} / \mathrm{ml}$ antidigoxygenin antibody alkaline phosphatase conjugate (Boehringer-Mannheim Biochemicals). After three 10-min washes in PBT and subsequently, in solution containing $100 \mathrm{mM} \mathrm{NaCl}, 50 \mathrm{mM} \mathrm{MgCl}_{2}, 100 \mathrm{mM}$ Tris ( $\mathrm{pH} 9.5$ ), and $0.1 \%$ Tween20 (SMT), sections were incubated in the dark at room temperature for $60 \mathrm{~min}$ in SMT with addition of $175 \mu \mathrm{g} / \mathrm{ml}$ 5-bromo-4-chloro-3-indoylphosphate and $175 \mu \mathrm{g} / \mathrm{ml}$ 4-nitro blue tetrazolium chloride in $70 \%$ dimethylformamide (Boehringer-Mannheim Biochemicals). Sections were processed through PBS, graded alcohols, xylene, and air dried for $12 \mathrm{~h}$. Serial sections were analyzed using a sense riboprobe as a control for nonspecific hybridization. No signal could be detected in these control hybridizations.
Table I. Localization of CFTR-positive Nuclei in Rat Brain

\begin{tabular}{lcc}
\hline \multicolumn{1}{c}{ Nucleus } & Number & Stain \\
\hline Forebrain & & \\
Cortex & $*$ & $*$ \\
Claustrum & $*$ & $*$ \\
Olfactory tubercle & $* *$ & $* *$ \\
Nucleus of the diagonal band & $* *$ & $* *$ \\
Amygdaloid nucleus & $* *$ & $* *$ \\
Hippocampus & $*$ & $*$ \\
Bed nucleus of the stria terminalis & & \\
Diencephalon & $* * *$ & $* * *$ \\
Paraventricular thalamic nucleus & $* *$ & $* *$ \\
Central medial thalamic nucleus & $*$ & $*$ \\
Rhomboid thalamic nucleus & $*$ & $*$ \\
Reuniens thalamic nucleus & $*$ & $*$ \\
Paraventricular hypothalamic nucleus & $*$ & $*$ \\
Lateral hypothalamic nucleus & $*$ & $*$ \\
$\quad$ Ventromedial hypothalamic nucleus & & \\
Midbrain & $* *$ & $* *$ \\
Cuneiform nucleus & $*$ & $*$ \\
Substantia nigra, reticular part & & \\
Pons & $* * *$ & $* * *$ \\
Lateral parabrachial nucleus & & \\
Medulla oblongata & $* *$ & $* *$ \\
Parvocellular reticular nucleus & $*$ & $* *$ \\
Nucleus of the solitary tract & $*$ & \\
Spinal trigeminal nucleus & & \\
\hline
\end{tabular}

Number: $*<10$ cells/section; $* * 10-20$ cells/section; $* * *>30$ cells/ section. Stain: ${ }^{*}$ light: $<2$ dark cells are visualized; $* *$ dark: cells are darkly stained; $* * *$ very dark; multiple cells are darkly-stained.

\section{Results}

Epitope mapping and specificity of antibodies. To confirm specificity, two antibodies, referred to as pAb3145 and pAb3147, were mapped with increasing size peptide sequences, as described in Methods. pAb3145 is a monospecific antibody to the sequence, EEVQDTRL, which exactly matches the mapping of $\alpha-1468$ produced by Cohn and colleagues $(23,24)$ (Fig. 1 ). pAb3147 consists of two peptide antibodies specific for sequences, KEETEE and EVQDTRL, comprising the whole peptide antigen (Fig. 1). Epitope mapping of monoclonal antibody, mAb24-1 (Genzyme Corp.) against CFTR, revealed similar but not exact epitope specificity as pAb3145.

Immunocytochemical localization of CFTR in rat brain. CFTR immunoreactive neurons were widely distributed throughout the entire rat brain and particularly, strong immunocytochemical staining is present in the diencephalon and limbic system (Table I). Prominent labeling was evident within neuronal soma and dendrites in the limbic system, including the paraventricular nuclei of the hypothalamus and thalamus, lateral parabrachial nucleus of the pons, reticular formation, amygdaloid nucleus, and the nucleus of the solitarius tract (Table I). In coronal and sagittal sections of rat brain after incubation with pAb3145, CFTR immunoreactivity is shown as dense uniform labeling within the cell bodies without any distinct background staining, specifically in the hippocampus (Fig. $2 A$ ). In tissue 

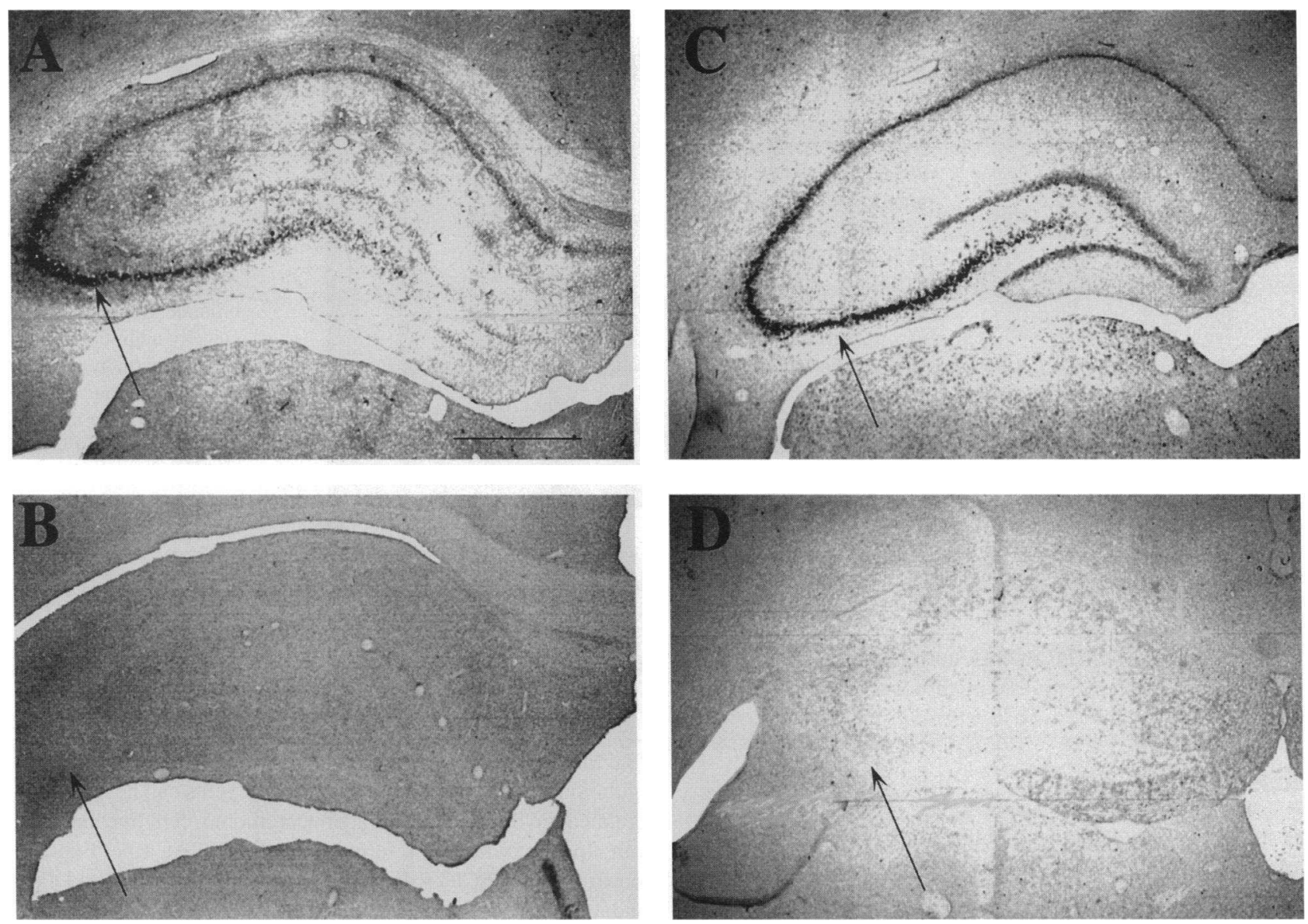

Figure 2. Immunocytochemical localization of CFTR protein and in situ labeling of CFTR mRNA in the hippocampal formation of rat brain. Either fresh frozen sections of rat brain were immunostained with anti-CFTR polyclonal antibody, pAb3145, in the absence of pAb3145 or processed for in situ labeling as described in Methods $(A)$ pAb3145 incubated brain sections revealing intense neuronal cell labeling throughout the pyramidal layer; $(B)$ in situ antisense labeling of CFTR mRNA showing equivalent staining of the pyramidal layer of the hippocampus; $(C)$ absence of pAb3145 incubation revealing no specific label within the hippocampal formation; $(D)$ sense probe labeling of hippocampus showing absence of any specific CFTR label. Scale bar $=1 \mathrm{~mm}$.

sections pAb3145 gave more accentuated staining than pAb3147; but there were not differences in the localization of CFTR labeling with either antibody preparation.

CFTR protein is identified throughout multiple neurons of specific nuclei and concordant to CFTR mRNA expression (Fig. $2 B$ and see Fig. 6). Fig. $2 B$ and $D$ reflect the antisense and sense CFTR riboprobe staining of the hippocampal formation. Specific labeling of neurons in the pyramidal layer of the hippocampus is identically expressed as seen in the immunocytochemical staining with the primary antibody, pAb3145 and with the CFTR antisense probe (Fig. $2 A$ and $B$ ). Specificity of labeling of CFTR within brain was confirmed by peptide preincubation with antibody and deletion of pAb3145, before subsequent tissue processing (Fig. $2 C$ ). The deletion either of primary or secondary antibody also led to disappearance of specific neuronal staining (data not shown). We did not detect any CFTR immunoreactivity within the choroid plexus or ependymal cells lining the ventricles (34). However, without the specific dissection of the choroid plexus, CFTR immunoreactivity cannot be excluded.

Identification of RT-PCR products. We detected the expres- sion of CFTR mRNA by RT-PCR and Southern blot analysis. Amplification of CFTR from rat brain RNA yielded the same size fragment, $258 \mathrm{bp}$, as produced through RT-PCR of the 3T3-CFTR RNA and of the full-length human CFTR cDNA clone, pMT-CFTR. Appropriate water control yielded no amplification; and the kanamycin positive RNA control yielded the expected 1.2-kb size product (Figs. 3 and 4). Nested PCR amplified products were identical matches to positive controls by size, 110 bp (Fig. 5); insert sequence of the RBCFTR14-1 clone showed $100 \%$ homology to the rat CFTR sequence (data not shown) (32).

Localization of CFTR $m R N A$ in rat brain. In situ hybridization was performed to localize CFTR mRNA within rat brain. There was striking expression of CFTR mRNA throughout the diencephalon, reticular formation, and the limbic system, including the hippocampal formation (Fig. 1). In addition strong cytoplasmic staining of neurons in the paraventricular nuclei of the hypothalamus and thalamus and the supraoptic nuclei was noted (Fig. 6, A-D). As a control for specificity of the antisense CFTR riboprobe, serial sections were hybridized with a sense CFTR probe but produced no specific signal (Fig. $6 E-G$ ). 


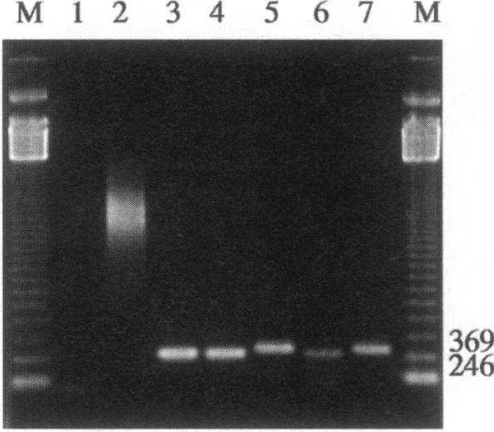

onagarose gel. The CFTR RT-PCR gave a 258-bp product and the tubulin RT-PCR gave a 288-bp product as expected. Sequence homology of the CFTR product amplified in lanes 3, 4, and 6 was identical to either the human and rat CFTR sequence (see text). Lanes: (1) water negative control; (2) kanamycin positive control; (3) pMT-CFTR; (4) 3T3-CFTR; (5) 3T3-CFTR tubulin; (6) rat brain CFTR; (7) rat brain tubulin; $(M)$ 123-bp DNA ladder (GIBCO BRL).

Identical expression of CFTR mRNA correlated with the localization of CFTR protein expression throughout the brain as depicted in Table I.

\section{Discussion}

In this study we have demonstrated the concordance of expression of CFTR mRNA and protein within neuronal cell bodies and dendrites of rat brain. Previously, our data suggested that CFTR protein is expressed within subcellular compartments, possibly within synaptic or clathrin-coated vesicles $(21)$. The regulation of neuropeptide secretion is dependent upon membrane trafficking of clathrin-coated vesicles and other membrane compartments. Whether CFTR is necessary for proper processing of neurotransmitter packaging is presently unknown. The role of CFTR in the regulation of membrane trafficking has recently been explored to define the cellular pathobiology

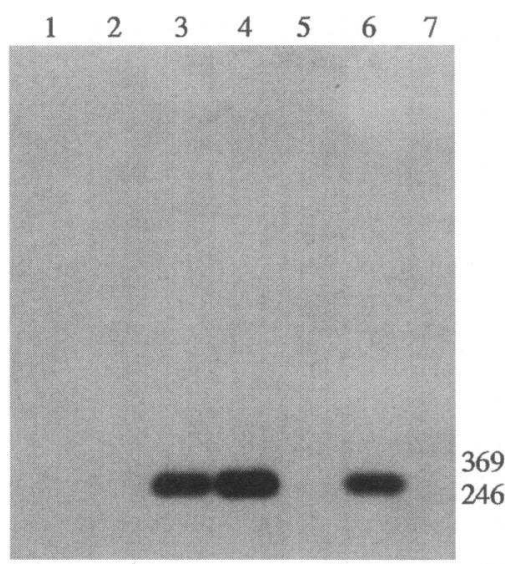

Figure 4. Southern blot analysis of CFTR and tubulin RT-PCR products from rat brain and $3 \mathrm{~T} 3$ CFTR RNA. RT-PCR amplified products were blotted to nitrocellulose, cross-linked by exposure to ultraviolet light and detected using a fluorescein-labeled oligonucleotide chosen as a nested internal nucleotide sequence of the first strand antisense probe. Development of the blot was performed through en-

hanced chemiluminescence (Amersham). No nonspecific amplification or hybridization was visible. Lanes: (1) water negative control; (2) kanamycin-positive reverse transcription control; (3) pMT-CFTR; (4) 3T3-CFTR; (5) 3T3-CFTR tubulin; (6) rat brain CFTR; (7) rat brain tubulin. Molecular weight markers are visualized to right of figure.

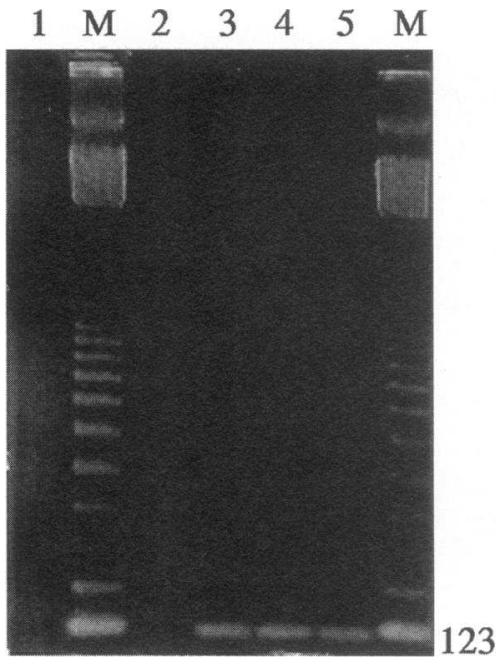

Figure 5. Agarose gel electrophoresis of nested PCR products. Nested PCR amplification of purified RT-PCR products was performed using the original sense primer and a nested antisense primer. The products were stained directly on the gel using ethidium bromide. Some nonspecifically amplified products are partially visible in lanes 3,4 , and 5 . The specificity of the nested PCR amplification was confirmed by cloning the rat brain nested PCR product into the pGEM-

$\mathrm{T}$ expression vector and analyzing by automated fluorescence sequencing revealing $100 \%$ homology to the rat CFTR sequence. Lanes: (1) water negative control; (2) purified water negative control from RTPCR; (3) pMT-CFTR; (4) 3T3-CF; (5) rat brain; (M) 123-bp DNA ladder (GIBCO BRL).

of CF. Bradbury et al. have shown that cAMP-dependent CFTR regulation of endocytosis and exocytosis events can be normally regulated in the pancreatic adenocarcinoma cell line derived from a patient with CF, referred to as the CFPAC line. Expression of abnormal CFTR leads to decreased exocytosis and $\mathrm{Cl}^{-}$ conductance (13-15). The relationship between CFTR function as a $\mathrm{Cl}^{-}$channel and regulator of membrane transport within the brain needs to be elucidated.

The function of CFTR expression within the hypothalamus, thalamus, amygdala, and limbic system remains unknown. These areas regulate food intake, energy utilization, and metabolic rate set points. Children with CF exhibit increased energy expenditure, failure to thrive, growth failure, and malnutrition leading to decreased survival. Increased energy expenditure cannot wholly be explained by the pulmonary or other systemic manifestations of $\mathrm{CF}$ and may reflect genotype-specific disease $(7,8,35)$. The localization of CFTR to brain regions regulating food intake, energy expenditure, salt and water balance, pancreatic endocrine secretion, and blood glucose concentration is intriguing (36-38).

A genotype-specific expression of mutant CFTR in brain may alter vesicle trafficking of neuropeptides in brain regions involved in regulation of homeostatic functions and energy utilization. Multiple neurotransmitters, including neurotensin, cholecystokinin, and neuropeptide Y (NPY), have been shown to mediate feeding and drinking behaviors in animals and are expressed within the hypothalamus and thalamus. Calza and colleagues have demonstrated that the increase in NPY-like material in the paraventricular nuclei of the hypothalamus in starved rats could be due to an increase of NPY synthesis or to a decrease in NPY release (39). Injection of NPY into the paraventricular nucleus of the hypothalamus stimulates drinking and feeding behaviors in animals. Observations of obese Zucker rats revealed increases in NPY in multiple nuclei of the hypothalamus (40). Increased NPY occurs partially because of a decrease of peripheral satiety signals, i.e., cholecystokinin. As a potent anorectic agent acting 

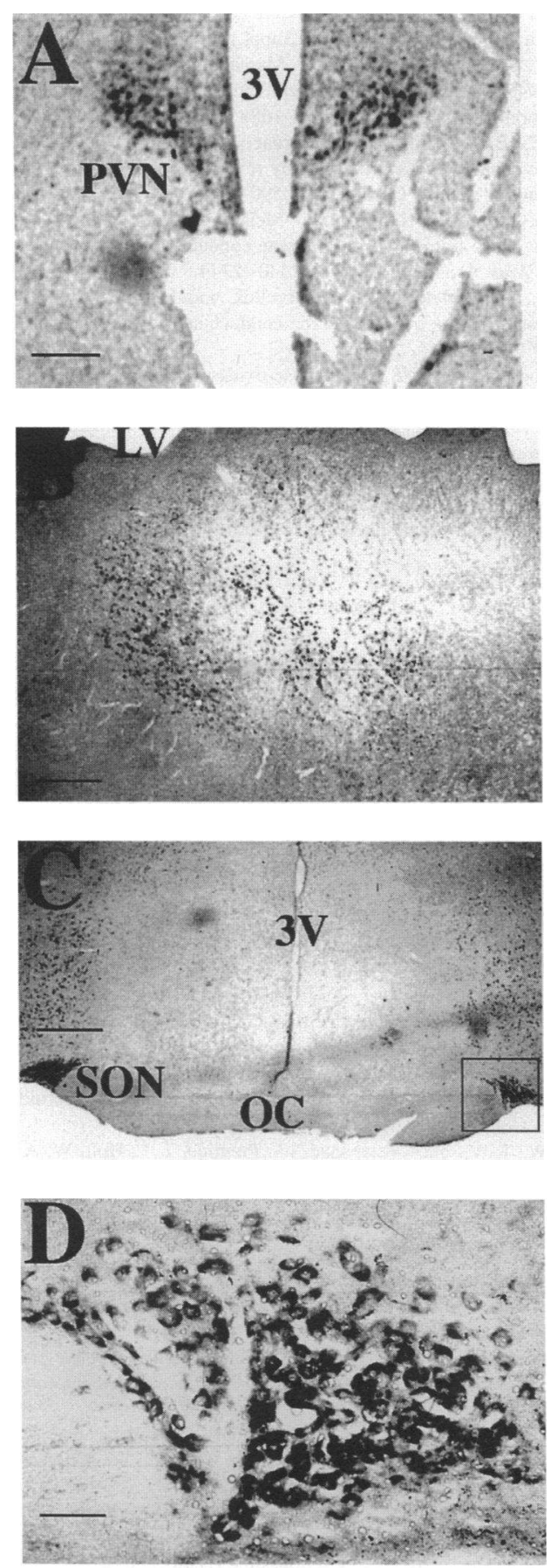
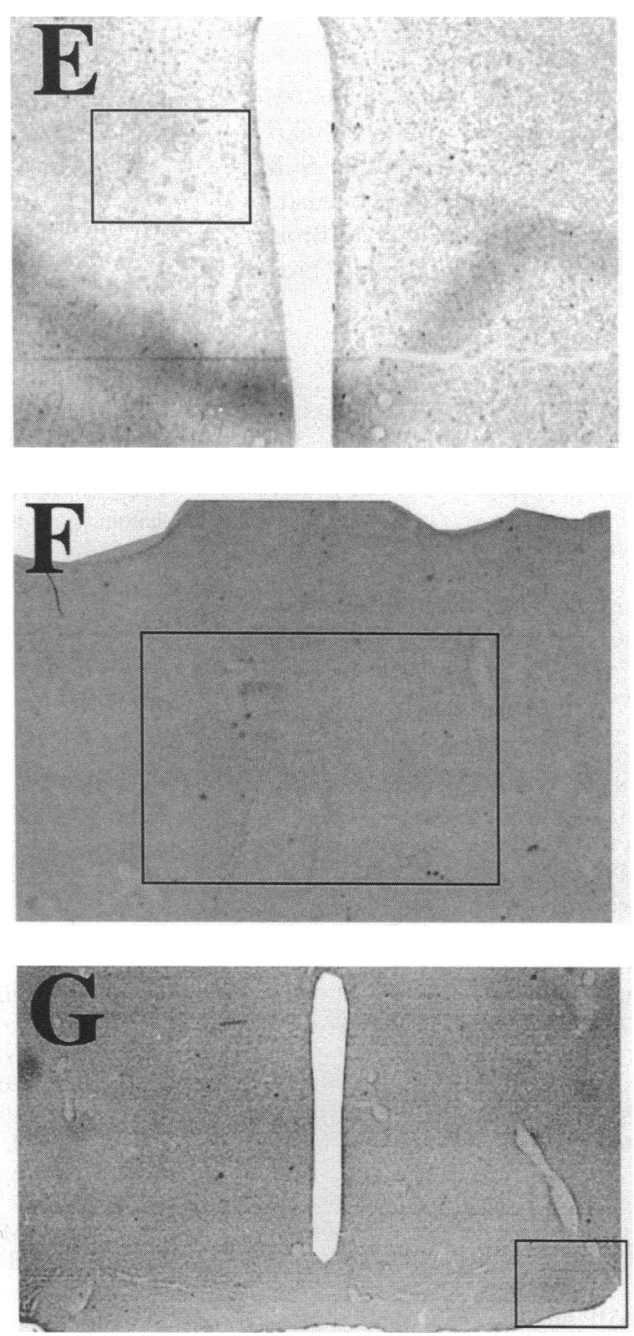

Figure 6. In situ hybridization of CFTR mRNA in rat brain. 30- $\mu \mathrm{m}$ sections of rat brain were hybridized to $2.5 \mu \mathrm{g} / \mathrm{ml}$ digoxygenin-labeled sense $(E, F$, and $G)$ or antisense $(A, B, C$, and $D)$ cRNA probes developed against cloned rat brain CFTR in pGEM-T expression vector. $30-\mu \mathrm{m}$ thick sections were developed with alkaline phosphatase-dependent colorimetric reaction. Antisense probes produced strong signal in cell bodies while the sense riboprobe produced no specific signal. Specific strong signal is demonstrated in the paraventricular nuclei of the hypothalamus and thalamus $(A$ and $B)$ as well as in the supraoptic nuclei ( $C$ and $D$ ). In $D$ the supraoptic nucleus reveals strong cytoplasmic label of the neuronal soma. Scale bar in $(A)$ $=0.05 \mathrm{~mm} ;(B)=0.05 \mathrm{~mm} ;(C)$ $=0.05 \mu \mathrm{mm} ;(D)=5 \mu \mathrm{m} . A$ and $E ; B$ and $F$; and $C$ and $G$ are at the same magnifications. $3 \mathrm{~V}$, third ventricle; PVN, paraventricular nucleus; $L V$, lateral ventricle; SON, supraoptic nucleus; OC, optic chiasm. on the paraventricular nucleus in the central hypothalamus, NPY may play a pivotal role in the pathogenesis of this abnormal physiological function $(41,42)$.

Neurotensin is known to cause anorexia and increased energy expenditure when injected into the central hypothalamus of rats $(40,43)$. Merchenthaler et al. has established that $70 \%$ of neurotensin-immunoreactive neurons within the arcuate nucleus, the paraventricular area, and the paraventricular nucleus send axons that terminate on portal capillaries of the median eminence (43). The regulation and maintenance of homeostatic functions is in part regulated by the pituitary gland and whose function may be affected by the expression of CFTR. No data presently exists regarding expression of CFTR within the pituitary.

Whether CFTR regulates neuropeptide secretion must be addressed through colocalization studies of CFTR with cholecystokinin, NPY, and neurotensin in rat and human brains. The prospect of understanding some of the protean manifestations of $\mathrm{CF}$, including growth failure and increased resting energy expenditure, may be related to the molecular and cellular dysfunction of CFTR in brain. We propose that abnormal energy utilization may result from dysregulation of neuropeptide secretion by mutant CFTR in the hypothalamus, thalamus, and the limbic system. 


\section{Acknowledgments}

We thank Dr. David Herrick for his critical review of the manuscript.

This work was supported by a Physician Scientist Award, DK02077 to A. E. Mulberg and RO1 awards DK44487 and DK34928 to S. M. Altschuler and D. M. Jefferson, a Robert Wood Johnson Foundation Award, HD28815 from the National Institutes of Health to D. L. Broussard and grant DK44861 to D. M. Jefferson from the Cystic Fibrosis Foundation.

\section{References}

1. Boat, T., M. Welsh, and A. Beaudet. 1989. Cystic fibrosis. In The Metabolic Basis of Inherited Disease. C. Scriver, A. Beaudet, W. Sly, and D. Valle, editors. McGraw Hill Inc., New York. 2649-2860.

2. Tsui, L.-C. 1992. The spectrum of cystic fibrosis mutations. Trends Genet. 8:392-398.

3. Lloyd-Still, J. D. ed. 1983. Textbook of Cystic Fibrosis. John Wright and Sons, Ltd., Bristol, United Kingdom. 498 pp.

4. Lloyd-Still, J. D. Cystic fibrosis. 1989. In Textbook of Gastroenterology and Nutrition in Infancy. E. Lebenthal, editor. 2nd ed. Raven Press, Ltd., New York. 831-876.

5. Buchdahl, R. M., M. Cox, C. Fulleylove, J. L. Marchand, A. M. Tomkins, M. J. Brueton, and J. O. Warner. 1988. Increased resting energy expenditure in cystic fibrosis. J. Appl. Physiol. 64:1810-1816.

6. Buchdahl, R. M., C. Fulleylove, J. L. Marchant, and J. O. Warner. 1989. Energy and nutrient intakes in cystic fibrosis. Arch. Dis. Child. 64:373-378.

7. O'Rawe, A., J. McIntosh, J. A. Dodge, D. J. H. Brock, A. O. B. Richard, R. Ward, and A. T. S. Macpherson. 1992. Increased energy expenditure in cystic fibrosis is associated with specific mutations. Clin. Sci. 82:71-76.

8. Tomezsko, J. L., V. A. Stallings, D. A. Kawchak, J. E. Goin, G. Diamond, and T. F. Scanlin. 1994. Energy expenditure and genotype of children with cystic fibrosis. Pediatr. Res. 35:451-460.

9. Rommens, J. M., M. C. Iannuzzi, B. Kerem, M. L. Drumm, G. Melmer, M. Dean, R. Rozmahel, J. L. Cole, D. Kennedy, N. Hidaka, et al. 1989. Identification of the cystic fibrosis gene: chromosome walking and jumping. Science (Wash. DC). 245:1059-1065

10. Egan, M. T. Flotte, S. Afione, R. Solow, P. L. Zeitlin, B. J. Carter, and W. B. Guggino. 1992. Defective regulation of outwardly rectifying Cl- channels by protein kinase A corrected by insertion of CFTR. Nature (Lond.). 358:581584.

11. Smith, J. J., and M. J. Welsh. 1992. cAMP stimulates bicarbonate secretion across normal, but not cystic fibrosis airway epithelia. J. Clin. Invest. 89:11481153.

12. Hasegawa, H., W. Skach, O. Baker, M. C. Calayag, V. Lingappa, and A. S. Verkman. 1992. A multifunctional aqueous channel formed by CFTR Science (Wash. DC). 258:1477-1479.

13. Bradbury, N. A., T. Jilling, G. Berta, E. J. Sorscher, R. J. Bridges, and K. L. Kirk. 1992. Regulation of plasma membrane recycling by CFTR. Science (Wash. DC). 256:530-532.

14. Bradbury, N. A., T. Jilling, K. L. Kirk, and R. J. Bridges. 1992. Regulated endocytosis in a chloride secretory epithelial cell line. Am. J. Physiol. 262(Cell Physiol. 31):C752-C759.

15. Bradbury, N. A., J. A. Cohn, C. J. Venglarik, and R. J. Bridges. 1994. Biochemical and biophysical identification of the cystic fibrosis transmembrane conductance regulator chloride channel as components of endocytic clathrincoated vesicles. J. Biol. Chem. 269:8296-8302.

16. Forgac, M. 1989. Structure and function of vacuolar class of ATP-driven proton pumps. Physiol. Rev. 69:765-796.

17. Marino, C. R., and P. Webster. 1993. Ultrastructural localization of CFTR to endosomes in a ductal epithelium. Cystic Fibrosis Conference. Dallas, Texas: Wiley-Liss: 8.

18. Lukacs, G. L., X.-B. Chang, N. Kartner, O. D. Rotstein, J. R. Riordan, and S. Grinstein. 1992. The cystic fibrosis transmembrane regulator is present and functional in endosomes. J. Biol. Chem. 267:14568-14572.

19. Barasch, J., B. Kiss, A. Prince, L. Saiman, D. Gruenert, and Q. Al-Awqati. 1991. Defective acidification of intracellular organelles in cystic fibrosis. Nature (Lond.). 352:70-73.
20. Barasch, J., and Q. Al-Awqati. 1993. Defective acidification of the biosynthetic pathway in cystic fibrosis. J. Cell Sci. 17(Suppl.):229-233.

21. Mulberg, A. E., E. B. Wiedner, X. Bao, J. Marshall, D. M. Jefferson, and S. M. Altschuler. 1994. Cystic fibrosis transmembrane conductance regulator protein expression in brain. Neuroreport. 5:1684-1688.

22. Mulberg, A. E., B. M. Tulk, and M. Forgac. 1991. Modulation of the coated vesicle chloride channel and acidification by reversible protein kinase Adependent phosphorylation. J. Biol. Chem. 266:20590-20593.

23. Cohn, J. A., A. C. Nairn, C. R. Marino, O. Melhus, and J. A. Cohn. 1992. Characterization of the cystic fibrosis transmembrane conductance regulator in a colonocyte line. Proc. Natl. Acad. Sci. USA. 89:2340-2344.

24. Marino, C. R., L. M. Matovcik, F. S. Gorelick, and J. A. Cohn. 1991. Localization of the cystic fibrosis transmembrane conductance regulator in pancreas. J. Clin. Invest. 88:712-716.

25. Shu, S., G. Ju, and L. Fan. 1988. The glucose-oxidase-DAB-nickel method in peroxidase histochemistry of the nervous system. Neurosci. Lett. 85:169-171.

26. Lee, B. H., R. B., H.-S. Lee, R. R. Miselis, and S. M. Altschuler. 1992. Calcitonin gene-related peptide in nucleus ambiguus motoneurons in rat: viscerotopic organization. J. Comp. Neurol. 320:531-543.

27. Chomczynski, P., and N. Sacchi. 1987. Single step method of RNA isolation by acid guanidinium thiocyanate-phenol-chloroform extraction. Anal. Biochem. 162:156-159.

28. Sambrook, J., E. F. Fritsch, and T. Maniatis, editors. 1989. Molecular cloning: A Laboratory Manual. Cold Spring Harbor Laboratory, Cold Spring Harbor, NY. 7.18-7.25.

29. McDonald, T. V., P. T. Nghiem, P. Gardner, and C. L. Martens. 1992. Human lymphocytes transcribe the cystic fibrosis transmembrane conductance regulator gene and exhibit CF-defective cAMP-regulated chloride current. J. Biol. Chem. 267:3242-3248.

30. Cowan, N. J., P. R. Dobner, E. V. Fuchs, and D. W. Cleveland. 1983. Expression of human alpha-tubulin genes: interspecies conservation of 3 '-untranslated regions. Mol. Cell. Biol. 3:1738-1745.

31. Lewis, S. A., M. G.-S. Lee, and N. J. Cowan. 1985. Five mouse tubulin isotypes and their regulated expression during development. J. Cell Biol. 101:852-861.

32. Fiedler, M. A., Z. K. Nemecz, and G. E. Shull. 1992. Cloning and sequence analysis of rat cystic fibrosis transmembrane conductance regulator. Am. J. Physiol. 262(Lung Cell Mol. Physiol. 6):L779-L784.

33. Broussard, D. L., E. B. Wiedner, X. Li, and S. M. Altschuler. 1994. NMDAR1 mRNA expression in the brainstem circuit controlling esophageal peristalsis. Mol. Brain Res. 27:329-332.

34. Hincke, M. T., and A. C. Nairn. 1993. Cystic fibrosis transmembrane conductance regulator is found within brain ventricular epithelium and choroid plexus. Cystic Fibrosis Conference. Dallas, Texas: Wiley-Liss: 207.

35. Shepherd, R. W., L. Vasques-Velansquez, A. Prentice, T. L. Holt, W. A. Coward, and A. Lucas. 1988. Increased energy expenditure in young children with cystic fibrosis. Lancet i:1300-1303.

36. Hyde, T. M., and R. R. Miselis. 1983. Effects of area postrema/caudal medical nucleus of solitary tract lesions on food intake and body weight. Am. J. Physiol. 244(Regulatory Integrative Comp. Physiol. 13):R577-R587.

37. Miselis, R. R., T. M. Hyde, and R. E. Shapiro. 1984. Area postrema and adjacent solitary nucleus in water and energy balance. Fed. Proc. 43:2969-2971.

38. Hyde, T. M., and R. R. Miselis. 1984. Area postrema and adjacent neucleus of the solitary tract in water and sodium balance. Am. J. Physiol. 247(Regulatory Integrative Comp. Physiol. 16):R173-R182.

39. Calza, L., L. Giardino, N. B. Zanni, S. Galetti, F. Protopapa, and A. Velardo. 1989. Increase of neuropeptide Y-like immunoreactivity in the paraventricular nucleus of fasting rats. Neurosci. Lett. 104:99-104.

40. Williams, G., H. Cardoso, Y. C. Lee, M. A. Chatei, P. R. Flatt, G. J. Barla, and S. R. Bloom. 1991. Reduced hypothalamic neurotensin concentrations in the genetically obese diabetic (ob/ob) mouse: possible relationship to obesity. Metab. Clin. Exp. 40:1112-1116.

41. Farouk, M., J. G. Geoghegan, R. S. Pruthi, H. J. Thomson, T. N. Pappas, and W. C. Meyers. 1992. Intracerebroventricular neuropeptide Y stimulates bile secretion via a vagal mechanism. Gut. 33:1562-1565.

42. Pages, N., M. Orosco, C. Rouch, O. Yao, C. Jacquot, and C. Bohuon. 1992. Fasting affects more markedly neuropeptide $\mathrm{Y}$ than monoamines in the rat brain. Pharmacol. Biochem. Behav. 44:71-75.

43. Merchenthaler, I., and D. E. Lennard. 1991. The hypophysiotropic neurotensin-immunoreactive neuronal system of the rat brain. Endocrinology. 129:2875-2880. 